\title{
Study on Precipitation Forecast and Testing Methods of Numerical Forecast in Fuxin Area
}

\author{
Xu Zhang, Ji Liu, Yue Gao, Xiaotong Yang \\ Fuxin Meteorological Bureau, Fuxin, China \\ Email:zxu521@126.com
}

How to cite this paper: Zhang, X., Liu, J., Gao, Y. and Yang, X.T. (2017) Study on Precipitation Forecast and Testing Methods of Numerical Forecast in Fuxin Area. Journal of Geoscience and Environment Protection, 5, 32-38.

https://doi.org/10.4236/gep.2017.57004

Received: April 7, 2017

Accepted: July 8, 2017

Published: July 11, 2017

Copyright $\odot 2017$ by author and Scientific Research Publishing Inc. This work is licensed under the Creative Commons Attribution International License (CC BY 4.0).

http://creativecommons.org/licenses/by/4.0/

\section{Open Access}

\begin{abstract}
This research uses Japan facsimile data in May-September of 2011-2015 in Fumeng and Zhangwu County of Fuxin, Liaoning, China as the site selection for high altitude NECV circulation background, using statistical and synoptic methods testing the combination of test and Analysis on Japanese numerical precipitation prediction and error. The prediction equation of cold vortex precipitation in the region is established by SPSS software. It is predicted whether the product predicts precipitation, water vapor condition and vertical velocity according to the Japanese numerical forecast. The results show that the fitting rate is $88 \%$ in the past 5 years, and the rate of cold vortex precipitation in the summer of 2016 is $89 \%$.
\end{abstract}

\section{Keywords}

Japan Fax Map, Northeast Cold Vortex, Precipitation Test, Forecasting Method

\section{Introduction}

With the methods of our forecast upgrade, types of numerical prediction for the forecasters are more and more. For Liaoning, the Japanese numerical forecast product is one of the important and effective guidance products, whether it is the Eurasian mid high latitude circulation situation forecast, or $850 \mathrm{hPa}$ low level jet position. The maximum wind velocity of $700 \mathrm{hPa}$ vertical ascending movement center value, position prediction, is relatively accurate. There are a lot of researchers in Japan that have verified numerical prediction and live in a large amount of work. Gao Songying [1] used the Japanese numerical forecast product to carry on the weather test and the error analysis to the Dandong rainstorm forecast; Yin Shao [2] used the SPSS statistical software to establish the 24-hour extreme temperature forecast in Changchun area, the objective and automation 
of temperature forecasting; Zhang Guiying [3] based on the Japanese facsimile map and Naiman single station precipitation data, the study of its application in single station precipitation forecast; Xu Min [4] study found that: Japan numerical forecast products for $\geq 10.0 \mathrm{~mm}$ and $\geq 25.0 \mathrm{~mm}$ order precipitation forecast are higher $10.0 \%-40.0 \%$ TS score than other models; Wu Jin [5] according to the precipitation produced the Japanese numerical forecast and other numerical prediction, combined with the product as the foundation, by the statistical analysis method of inverse distance interpolation downscaling, so as to establish a multi model integrated model of summer precipitation forecast in Beijing area. The effect of improving the model prediction of precipitation is better than a single numerical model precipitation forecast. The northeastern cold vortex is an important weather system that causes sudden and severe convective weather in the northeastern region of China, which has a significant impact on the weather and climate in the northeastern region due to the low temperature chilling injury in the northeastern region, sustained rain and flood, hail and thunderstorms. Fuxin, located in the hilly area of western Liaoning Province, is the central city of northwest Liaoning province, China. However, there are few articles on the application and test of numerical forecasting in Japan under the background of northeast cold vortex, especially for Fuxin in Liaoning. this paper is devoted to the study of northeast cold vortex precipitation forecast test in Fuxin, Japan on the test accuracy of the cold vortex precipitation forecast, forecast equation of local cold vortex precipitation, to solve the problem of local precipitation forecast, due to the summer precipitation to produce cold vortex. Mainly in the 5 - 7 three months, 5 - 7 months is the crop sowing, seedling emergence, growth and development of the critical period, if it can be accurately forecast the cold vortex precipitation, not only for the local fine forecast to provide a foundation for predicting, in order to improve the accuracy of our city weather, but also to lay a good foundation for our city to spring etc. the agricultural production work.

\section{Data, Research Methods}

Selection of precipitation data from 2011 to 2015 May-September 24 h daily (20 $20 \mathrm{~h}$ ) precipitation more than $0.1 \mathrm{~mm}$ affected by the cold vortex precipitation, and precipitation over Japan facsimile date (FUFE502, 503), and the 8 or 20 day precipitation when $500 \mathrm{hPa}$ aerial images; calculated with statistical methods of Japanese numerical weather prediction the accuracy rate and false negative rate were empty, the center intensity contrast state chart and test of cold vortex, and the vortex moving path, and calculation of ground system with different precipitation accuracy. To establish local cold vortex precipitation forecast equation with SPSS software.

\section{Key Areas Identified}

This study is devoted to the cold vortex in the northeast China (so called "northeast cold vortex"), and Fuxin, Liaoning is located at the northeast China. So we choose Fuxin, Liaoning as the key areas identified. According to the rain- 
fall (more than $0.1 \mathrm{~mm}$ ) occurred on the same day, check the Anti Japan facsimile chart (FUFE502, 503) position $500 \mathrm{hPa}$ high altitude cold vortex $8 \mathrm{~h}$ or $20 \mathrm{~h}$ images, after 136 times of cold vortex process location analysis, to determine the final $38^{\circ} \mathrm{N}-52^{\circ} \mathrm{N}, 113^{\circ} \mathrm{E}-125^{\circ} \mathrm{E}$, as the key area of Fuxin cold vortex precipitation. If on the same day or the day before the cold vortex precipitation center in this area and that meet the conditions (see Figure 1).

\section{Inspection Situation}

\subsection{Precipitation Accuracy Test}

2011-2015 years 5 - 9 months of daily precipitation is greater than $0.1 \mathrm{~mm}$ the weather process. When the FUFE502503 is entered in the key areas in the cold vortex, Zhangwu has 125, the accuracy rate of Japanese numerical weather prediction is $83.2 \%$ and the vacancy rate is $7.2 \%$, false negative rate is $9.6 \%$, a total of 127 cold vortex precipitation process Fumeng accuracy of Japanese numerical forecast the $86.7 \%$ vacancy rate is $8.6 \%$, false negative rate is $4.7 \%$.

\subsection{Inspection of the Eddy Center Strength}

The 136 cold vortex process, forecast map and $500 \mathrm{hPa}$ altitude state chart of vortex center intensity difference 0 - 4 potential meter in Japan that accurate prediction of strength, by contrast, the center intensity accurately accounted for $89.7 \%$, forecast center than live weak accounted for $1.5 \%$, accounting for $7.4 \%$ of the live strong, when the cold vortex, forecast trough accounted for $2.1 \%$.

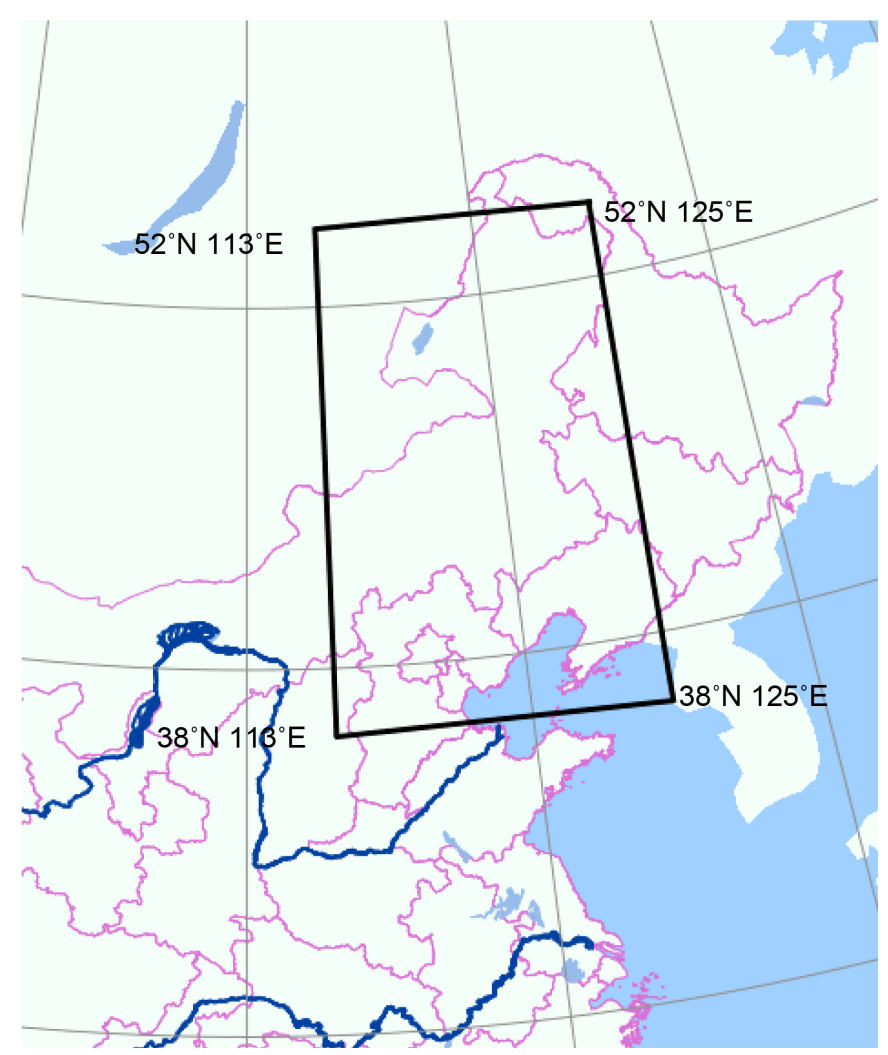

Figure 1. Key areas identified. 


\subsection{Cold Vortex Path Test}

Prediction of cold vortex motion path and live cold path basically the same (ignoring the difference of 2 latitude distance or distance) accounted for $85.3 \%$, forecast the eddy center position South North accounted for 5.15\% and 5.89\%, East West accounted for $2.2 \%$ and $1.46 \%$, reflecting the Japanese mobile location prediction of cold vortex more credible.

\subsection{Cold Vortex with Different Ground Systems}

We have access to the Japanese fax map, collected 136 cold vortex cases. The 136 cold vortex process, the ground is Mongolia cyclone (Mongolia low) cases accounted for 59, 38 low, trough 14, Jianghuai cyclone (North China) 7, weak high 5 , missing 13 times, the accuracy rate shown in Table 1.

Thus, the Japanese numerical forecast on the south to the system of high precipitation accuracy, followed by the Mongolia cyclone, the comparison of the two counties, Fuxin Weather Station is better than Zhangwu Weather Station.

\section{Establishment of Cold Vortex Precipitation Forecasting Equation}

The Fuxin area is forecast precipitation in a day before the $08 \mathrm{~h}$ Japanese fox forecast map or JFSFE03.bi0 JFSFE02.bi0 (Y/N), JFXFE572.bi0 and JFXFE573.bi0 on the wet area $\left(\mathrm{T}-\mathrm{Td}<4^{\circ} \mathrm{C}\right)$ the existence of JFXFE782.bi0 (Y/N), vertical velocity and JFXFE783.bi0 $(\mathrm{W})$ is less than $-7 \times 10^{-3} \mathrm{~m} / \mathrm{s}(\mathrm{Y} / \mathrm{N})$ results as three the main factors of Fuxin cold vortex precipitation forecast, named $\mathrm{X}_{1}, \mathrm{X}_{2}, \mathrm{X}_{3} . \mathrm{X}_{1}, \mathrm{X}_{2}$, $\mathrm{X}_{3}$ as the independent variable factor regression equation, respectively $(0,1)$ processing, calculation of independent variable factors using SPSS coefficient Statistics system, establish the forecasting of cold vortex precipitation in Fuxin area discriminant equation is: $\mathrm{Y}=0.462 \times \mathrm{X}_{1}+0.152 \times \mathrm{X}_{2}+0.01 \times \mathrm{X}_{3}+0.377$.

This study selected the fitting rate of better than $85 \%$ case history include the value of $\mathrm{Y}$ is determined as the critical value of equation ( $\mathrm{Yc}=0.839$ ), the correct rate is $88.3 \%$, the error rate is $11.7 \%$ (the vacancy rate $5.3 \%$, false negative rate 6.4\%). This draws the following conclusion: when $\mathrm{Y} \geq \mathrm{Yc}$, forecast for the next

Table 1 . The 136 cold vortex cases.

\begin{tabular}{|c|c|c|c|c|c|c|c|c|c|c|}
\hline & \multicolumn{2}{|c|}{$\begin{array}{l}\text { Mongolian } \\
\text { cyclone }\end{array}$} & \multicolumn{2}{|c|}{$\begin{array}{c}\text { Low pressure } \\
\text { type }\end{array}$} & \multicolumn{2}{|c|}{ Inverted slot } & \multicolumn{2}{|c|}{$\begin{array}{l}\text { Weak high } \\
\text { pressure }\end{array}$} & \multicolumn{2}{|c|}{$\begin{array}{c}\text { Huaibei } \\
\text { (North-China) } \\
\text { cyclone }\end{array}$} \\
\hline Fuxin County & \multicolumn{2}{|c|}{88.13} & \multicolumn{2}{|c|}{84.21} & \multicolumn{2}{|c|}{92.86} & \multicolumn{2}{|c|}{40} & \multicolumn{2}{|c|}{100} \\
\hline \multirow[t]{2}{*}{ Zhangwu County } & \multicolumn{2}{|c|}{86.44} & \multicolumn{2}{|c|}{86.84} & \multicolumn{2}{|c|}{85.7} & \multicolumn{2}{|c|}{60} & \multicolumn{2}{|c|}{85.7} \\
\hline & $\begin{array}{l}\text { False } \\
\text { alarm }\end{array}$ & Missed & $\begin{array}{l}\text { False } \\
\text { alarm }\end{array}$ & Missed & $\begin{array}{l}\text { False } \\
\text { alarm }\end{array}$ & Missed & $\begin{array}{l}\text { False } \\
\text { alarm }\end{array}$ & Missed & $\begin{array}{l}\text { False } \\
\text { alarm }\end{array}$ & Missed \\
\hline Fuxin County & 6.78 & 5.1 & 10.5 & 3.45 & 7.14 & 0 & 40 & 20 & 0 & 0 \\
\hline Zhangwu County & 5.1 & 3.39 & 7.89 & 5.26 & 7.14 & 7.14 & 20 & 20 & 0 & 14.3 \\
\hline
\end{tabular}


24 hours with precipitation, $\mathrm{Y}<\mathrm{Yc}$, the forecast for the next 24 hours without precipitation.

The statistics of the 2011-2015 year 5 - 8 months Fuxin meteorological station cold vortex precipitation forecast quality, the accuracy of $83.5 \%$ and the forecast equation established in this study to return the accuracy rate $(88.3 \%)$ was increased by $5.3 \%$, the cold vortex precipitation prediction in our city has been greatly improved.

\section{Application of the Test}

2016 year $4-7$ months, the city meteorological station based on the project platform for the production of cold vortex precipitation forecast 38 times (19 times each Fumeng county and Zhangwu county), the forecast accuracy rate reached $89.49 \%$, than the 2011-2015 improves the cold vortex precipitation $5.99 \%$. accurate prediction on May 3 - 5, May 23 - 25, the cold vortex precipitation weather process on June $10-115$ the agriculture of Fuxin has a significant impact, while carrying out the forecasting and early warning, the implementation of artificial rainfall, rainfall monitoring, meteorological services during the whole process of rain impact assessment, for the city's spring production smoothly, seedling emergence and crop Long development, facilities, agricultural production, avoiding disadvantages, disaster prevention and mitigation of meteorological science and technology support.

\section{Revised method}

Based on the experience of forecasters, we have given four revised methods. They are independent and acting together.

1) $1500 \mathrm{hPa}$ cold vortex center into $38^{\circ} \mathrm{N}-52^{\circ} \mathrm{N}, 113^{\circ} \mathrm{E}-125^{\circ} \mathrm{E}$, the center value of $576-536$ potential ten meters.

2) $700 \mathrm{hPa}$ at $35^{\circ} \mathrm{N}-50^{\circ} \mathrm{N}, 110^{\circ} \mathrm{E}-120^{\circ} \mathrm{E}$ with grooved or tangential lines. Vertical speed $\leq-7 \times 10^{-3} \mathrm{~m} / \mathrm{s}$.

3) $850 \mathrm{hPa}$ in $35^{\circ} \mathrm{N}-50^{\circ} \mathrm{N}, 115^{\circ} \mathrm{E}-125^{\circ} \mathrm{E}$ there is a clear wet zone $(\mathrm{T}-\mathrm{Td} \leq$ $4^{\circ} \mathrm{C}$ ) and warm and humid air.

4) On the ground map $38 \mathrm{~N}-44^{\circ} \mathrm{N}, 115^{\circ} \mathrm{E}-125^{\circ} \mathrm{E}$ there is cold front. (Jianghuai cyclone, inverted groove, Mongolian cyclone).

According to the above four is forecast according to the Japanese numerical forecast to cold vortex precipitation, in addition to the forecasters in the forecast also take into account the following factors which needs to combine a variety of numerical forecast (European numerical forecast, T639 numerical forecast, WRF, etc.), to analyze which forecast and the situation closer, which forecast path is more accurate. Then we take into account the above factors to draw the conclusion. We combine local climatic conditions to consider whether the underlying surface conditions are favorable for precipitation. Such as drought season, is not conducive to precipitation. On the contrary, the underlying surface of the more humid conditions is more conducive to the emergence of precipitation. 3) different numerical prediction will reflect the different characteristics in dif- 
ferent stages Point. For example, the Japanese numerical forecast in a certain period of cold vortex precipitation appeared false negative phenomenon, or offer more precipitation phenomenon; and the T639 numerical forecast of our country to the cold precipitation appears empty the phenomenon, which requires the forecaster in conditions and different background of the comprehensive analysis and judgment, there is a need to also by superior departments and consultation, so as to make the precipitation forecast more accurate.

\section{Conclusion}

1) The critical area of high-altitude cold vortex precipitation is determined, which is $38^{\circ} \mathrm{N}-52^{\circ} \mathrm{N}, 113^{\circ} \mathrm{E}-125^{\circ} \mathrm{E}$, which has played a certain role in the prediction of cold vortex precipitation in our city.

2) The accuracy precipitations of Japan's numerical forecast for Fumeng County and Zhangwu County are high, respectively $86.7 \%$ and $83.2 \%$, having some guiding significance.

3) In the process of 136 cold vortex tests, the numerical prediction of Japan has reached $90 \%$ accuracy rate for cold vortex center intensity and $85.3 \%$ for the cold vortex movement.

4) In the background of high altitude cold vortex and ground different field, the south cyclone data is more accurate to the prediction accuracy of precipitation in the two counties.

5) The cold vortex precipitation prediction equation is established, and the application effect is good and can be put into the business work.

Due to the "uncertainty" of the northeastern cold vortex, the forecaster's difficulty in the northeastern cold vortex precipitation is difficult to grasp, so that the forecast of the northeast cold vortex has become a difficult problem. In recent years, our meteorological workers, on the basis of the results of the previous studies, have carried on the research on the northeast cold vortex key area and its evolution law for the northeast cold vortex forecasting, and through the research, reveal the key features and system development of the northeast cold vortex characteristics, to improve the overall level of cold weather forecast.

\section{Acknowledgements}

This work was supported by the "Precipitation forecast test of northeast cold vortex in Fuxin area", one of the scientific research projects of Fuxin Meteorological Bureau.

\section{References}

[1] Liu, T.W., Li, H.L. and Gao, Y. (2011) Weather Test and Error Analysis of Japanese Numerical Products for Dandong Rainstorm Forecast. Storm Disasters, 30, 234-240.

[2] Ying, S. (2007) The Release of Numerical Prediction Products in Japan. Jilin Meteorology, 9, 21-22.

[3] Zhang, G.Y., Sun, D.L., Liu, J., Li, S.H. and Han, D.M. (2012) Application of Japanese Numerical Forecast Products in Single Station Precipitation Forecast. Modern 
Agricultural Science and Technology, 40, 28.

[4] Xu, M., Cong, B. and Liu, Y.J. (2016) Test and Evaluation of Five Numerical Models for Precipitation Forecast in Langfang Area. Journal of Meteorology and Environment, 32, 9-15.

[5] Wu, J., Fu, Z.Y., Wu, J.K., He, N. and Zhao, W. (2016) Application of Fall-Scale Integration of Summer Multi-Pattern Precipitation Forecast in Beijing. Meteorological Technology, 44, 55-60.

Submit or recommend next manuscript to SCIRP and we will provide best service for you:

Accepting pre-submission inquiries through Email, Facebook, LinkedIn, Twitter, etc. A wide selection of journals (inclusive of 9 subjects, more than 200 journals) Providing 24-hour high-quality service User-friendly online submission system Fair and swift peer-review system Efficient typesetting and proofreading procedure Display of the result of downloads and visits, as well as the number of cited articles Maximum dissemination of your research work

Submit your manuscript at: http://papersubmission.scirp.org/

Or contact gep@scirp.org 